\title{
Results From Finland's 2016 Report Card on Physical Activity for Children and Youth
}

\author{
Tuija H. Tammelin, Annaleena Aira, Matti Hakamäki, Pauliina Husu, Jouni Kallio, Sami Kokko, \\ Kaarlo Laine, Kati Lehtonen, Kaisu Mononen, Sanna Palomäki, Timo Ståhl, Arja Sääkslahti, \\ Jorma Tynjälä, and Katariina Kämppi
}

\begin{abstract}
Background: Finland's 2016 Report Card on Physical Activity for Children and Youth gathers and translates research results and assesses the status and promotion of physical activity (PA) among Finnish children and youth less than 18 years of age. This article summarizes the results and provides grades for 9 indicators. Methods: The working group evaluated the evidence and assigned grades of $A$ (highest, $81 \%$ to $100 \%$ ), $B, C, D$, or $F$ (lowest, $0 \%$ to $20 \%$ ) for 9 PA indicators using the Active Healthy Kids Canada Report Card development process. Results: The grades varied in Finland as follows: 1) Overall PA/fulfillment of recommendations $=D$, 2) Organized Sport Participation $=C$, 3) Active Play $=C$, 4) Active Transportation $=B$, 5) Sedentary Behaviors $=D, 6)$ Family and Peers $=C, 7)$ School $=B, 8)$ Community and the Built Environment $=B$, 9) Government $=B$. Conclusions: Despite good policies and programs to promote PA in Finland, children and youth overall PA levels are low, whereas their time spent sedentary is high. More effective interventions, operation models, concrete tools as well as environmental solutions are needed to support the work toward more physically active childhood and youth.
\end{abstract}

Keywords: policy, adolescent

Finland's 2016 Report Card on Physical Activity for Children and Youth has gathered and assessed research results on the status and promotion of physical activity (PA) among children and youth younger than 18 years, with a special focus on school-aged children, since 2010. The data that inform the results of Finland's 2016 Report Card should be considered within the following contextual factors. Finland is characterized by its relatively sparse population of 5.5 million people residing on 338,424 square kilometers. Of importance are Finnish residents' proximity to nature and a feeling of safety allowing children to move about freely within their neighborhoods. Finland is a circumpolar country with 4 different seasons featuring a wide annual temperature range. The land is typically covered by snow from December to March, and during the coldest days, the temperature may fall to $-30^{\circ} \mathrm{C}$. From late May to mid-September, the days are longer, and the warmest days of July can reach over $35^{\circ}$ C. ${ }^{1,2}$

Seasonal changes also affect the levels and types of children's PA (eg, children are less active in autumn and winter compared with spring and summer). ${ }^{3}$ In Finland, students go to school 5 days per week, from Monday to Friday. In general, school-aged children are more physically active during the weekdays compared with the weekends. ${ }^{3}$ In the Finnish school system, obligatory basic

Tammelin, Aira, Hakamäki, Kallio, Laine, Lehtonen, and Kämppi are with LIKES Research Centre for Physical Activity and Health, Finland. Husu is with The UKK Institute for Health Promotion Research, Finland. Kokko and Tynjälä are with the Research Centre for Health Promotion, Dept of Health Sciences, University of Jyväskylä, Finland. Mononen is with the Research Institute for Olympic Sports, Finland. Palomäki and Sääkslahti are with the Dept of Sport Sciences, University of Jyväskylä, Finland. Ståhl is with the National Institute for Health and Welfare, Finland. Tammelin (tuija.tammelin@likes.fi) is corresponding author. education encompasses 9 years (grades 1 to 9 ) beginning at the age of 7 with primary school (grades 1 to 6) followed by lower secondary school (grades 7 to 9) until 16 years of age. Before basic education, preprimary education is organized in day-care centers and schools for children aged 6 . After basic education, voluntary upper secondary education continues in upper secondary schools and vocational schools, with some students moving on to higher education in universities and polytechnics. In Finland, education is free at all levels, from preprimary to higher education. ${ }^{4}$

A key theme of the 2016 Report Card is to describe how different indicators contribute to support all children and youth to meet PA recommendations. National PA recommendations for school-aged children were established in 2008: 'All 7- to 18-year-olds should be physically active for at least 1 to 2 hours daily, continued periods of sitting for more than 2 hours at a time should be avoided, and screen time with entertainment media should be limited to 2 hours per day.' ${ }^{5}$

The national Finnish Schools on the Move (FSM) program was launched in 2010 to implement these national PA recommendations in all comprehensive schools and to make the school day more active and pleasant. There is widespread political acceptance of these actions to increase PA among children and youth in Finland. Currently, the FSM program is part of the government program and is a key project related to developing learning environments in basic education: "The 'Schools on the Move' project will be expanded across the country to ensure one hour of physical activity each day" (stated in May 2015). ${ }^{6}$ All actors at schools and day-cares, parents, friends, sports clubs, etc. are needed to encourage children and offer opportunities to children and youth to meet this minimum goal. This 60 minutes per day may accumulate by actively commuting to and from school, during physical education (PE) and physically active recesses at school, by participating in after-school activities organized by sport clubs and other associations, as well as by physically 
active play outdoors. In addition, municipalities play an important role in making decisions that encourage this common goal.

This article summarizes the most current evidence on the levels of PA and sedentary behavior among Finnish children and youth; further, it evaluates how Finland is doing as a country in promoting and facilitating PA opportunities among children and youth. The results will be used to support community-level improvements in PA by informing policies, programs, campaigns, and investments aimed to enhance opportunities for children and youth to participate in physical activities.

\section{Methods}

Finland's 2016 Report Card compilation process was coordinated by LIKES Research Centre for Physical Activity and Health and conducted in collaboration with 4 other research institutes: the University of Jyväskylä, the UKK Institute for Health Promotion Research, KIHU - the Research Institute for Olympic Sports and the National Institute for Health and Welfare. The working group included 20 specialists from different fields working with research, policy, or practice related to PA among children and youth. The working group evaluated the evidence and assigned grades for 9 PA indicators related to PA among Finnish children and youth: 1) Overall Physical Activity Levels, 2) Organized Sport Participation, 3) Active Play, 4) Active Transportation, 5) Sedentary Behaviors, 6) Family and Peers, 7) School, 8) Community and the Built Environment, and 9) Government. The working group assigned letter grades according to the following grading scheme (based on the proportion of children or institutes achieving the selected benchmark for each indicator): $A=81 \%$ to $100 \%, B=61 \%$ to $80 \%, C=41 \%$ to $60 \%, D$ $=21 \%$ to $40 \%$, and $F=0 \%$ to $20 \%$ (Table 1 ). The process followed the Active Healthy Kids Canada PA Report Card protocol. ${ }^{7}$

The main data sources related to the 9 indicators are presented in Table 2. The results are based on data measured since 2010 and published in both national research reports and international peer review journals. Results also include unpublished information from the most recent studies conducted in 2014 to 2016 that are based on personal communication with principal investigators of these studies. Since the first Finnish Report Card was published in 2014, the data have been updated with the results of traditional Finnish

\section{Table 1 Grades According to the Physical Activity Indicator in Finland's 2016 Report Card on Physical Activity for Children and Youth}

\begin{tabular}{lc}
\hline Indicator & Grades \\
\hline Overall Physical Activity Levels & $D$ \\
Organized Sport Participation & $C$ \\
Active Play & $C$ \\
Active Transportation & $B$ \\
Sedentary Behaviors & $D$ \\
Family and Peers & $C$ \\
School & $B$ \\
Community and the Built Environment & $B$ \\
Government Strategies and Investments & $B$ \\
\hline
\end{tabular}

Note. The grade for each indicator is based on the percentage of children and youth meeting a defined benchmark: $A=81-100 \%, B=61-80 \%, C=41-60 \%, D=$ $21-40 \%, F=0-20 \%$. surveys, data from a new national PA survey called the LIITU study, ${ }^{8}$ the FSM program, ${ }^{9}$ and recent studies of preschool children. ${ }^{10}$

\section{Results}

Finland's 2016 Report Card is the second assessment of PA. The grades assigned for the 2016 Report Card are summarized in Table 2 and its front cover is illustrated in Figure 1. The only change in grading compared with Finland's 2014 Report Card was observed in the indicator of active play. The grade of active play improved from $D$ in 2014 to $C$ in 2016 based on a wider set of available data.

\section{Discussion}

Despite good policies and programs to promote PA in Finland, the overall levels of activity for children and youth are low, whereas time spent sedentary is high. It is important to consider how different forms of PA and sedentary behavior, as well as different institutes and levels of administrations, could improve their contribution to the common national goal of 60 minutes of PA per day.

\section{Overall Physical Activity Levels: $\boldsymbol{D}$}

The grade $D(21 \%$ to $40 \%)$ describes the proportion of children who meet the minimum recommendation of engaging in at least 60 minutes of moderate-to-vigorous physical activity (MVPA) per day. The proportion of children achieving 60 minutes varies because different studies used different questionnaires, devices, and analysis techniques. Based on accelerometer measurements in one study, the proportion of children meeting the minimum recommendation varied between $16 \%$ in secondary school girls and $59 \%$ in primary school boys. ${ }^{11}$ The proportion of children engaging in at least 60 minutes of MVPA per day from 2010 to 2015 was $29 \%$ among 3 -year-old children, ${ }^{12} 49 \%$ among children in primary school (40\% in girls and $59 \%$ in boys), ${ }^{11}$ and $18 \%$ among adolescents in lower secondary school (16\% in girls and $22 \%$ in boys). ${ }^{11} \mathrm{~A}$ study in Naantali in 2013 had similar results: $35 \%$ of primary school students met the minimum recommendation. ${ }^{13,14}$ Using self-reports, the Health Behavior in School-Aged Children (HBSC) ${ }^{15}$ study in 2014 found that the proportion of children who had at least 60 minutes of MVPA 7 days per week reached $23 \%$ in girls and $33 \%$ in boys aged 11 to $15 ;^{16}$ in the LIITU study in 2016, these percentages reached $28 \%$ in girls and $37 \%$ in boys aged 9 to 15 years. ${ }^{17}$ Boys met the recommendation more often than girls, and the proportion of children meeting PA levels decreased as age increased. Nationwide data on objective levels and trends of overall PA are needed for children and youth. More solutions at the individual, social, and environmental level are needed in Finnish society to support overall more physically active lifestyles in young people.

\section{Organized Sport Participation: C}

The Organized Sport Participation indicator is graded $C$ (40\% to $60 \%$ ), as one-half of the children aged 7 to 18 years reported participation in sport club activities at least once per week in surveys and interviews. In Finland, sport club activities play a dominant role in the leisure-time activities of young people. Among children and adolescents aged 7 to $19,46 \%$ participate in sport club activities at least once per week (boys more often than girls, at $51 \%$ versus $41 \%$, respectively). ${ }^{18}$ Participation in organized sport decreases with age. Among preschool children aged 3 to 6 years, 57\% take part 

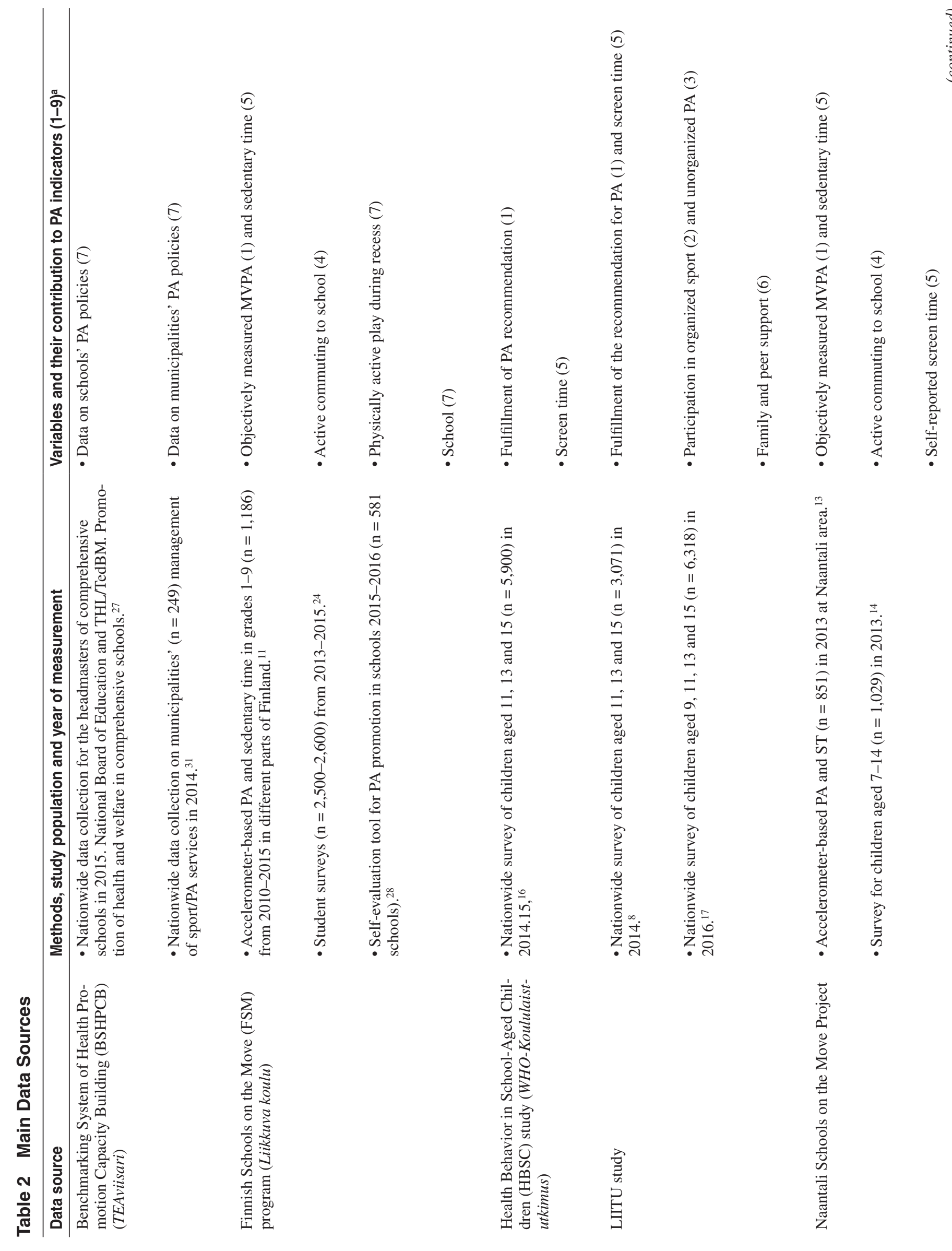

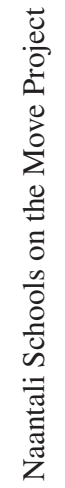




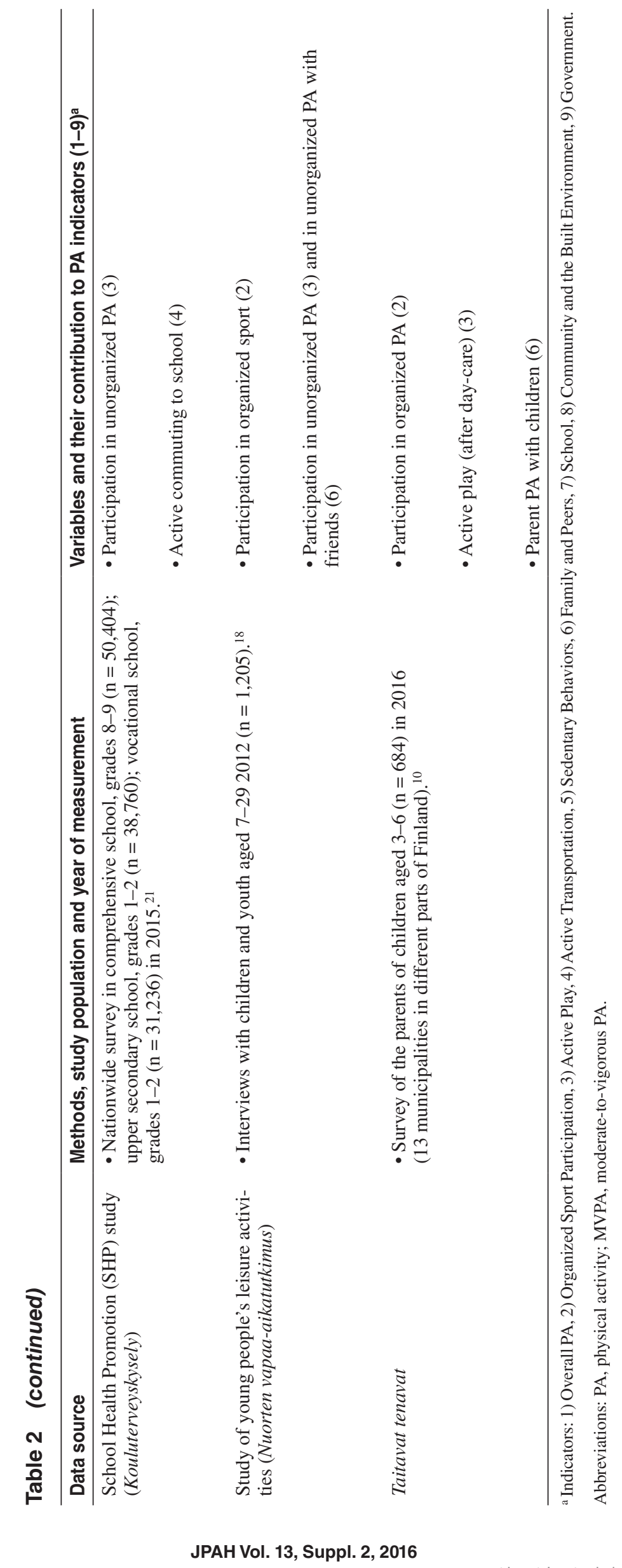




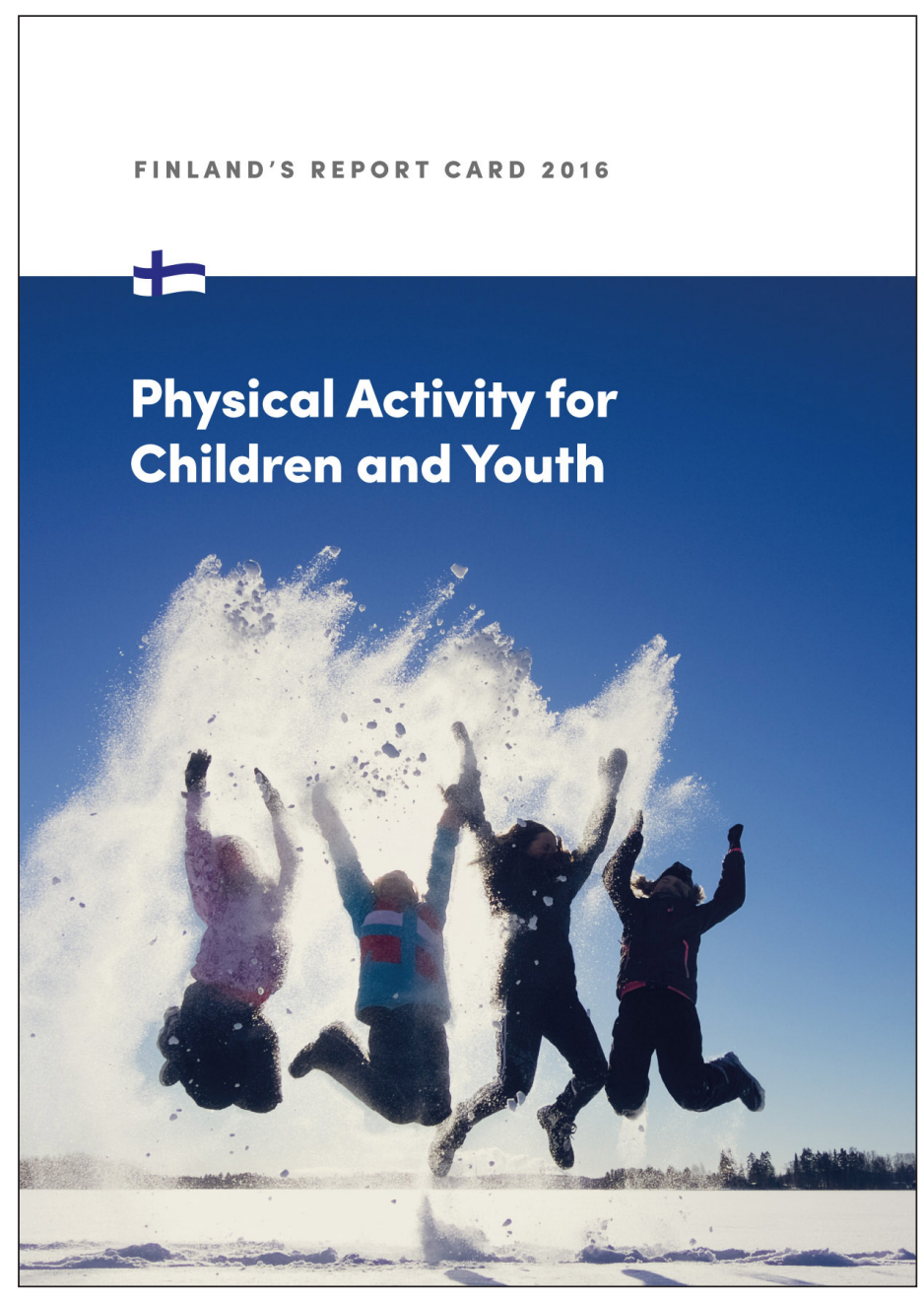

Figure 1 - Front cover of Finland's 2016 Report Card on Physical Activity for Children and Youth.

in some kind of organized sport, based on their parents' report. ${ }^{10}$ The proportion of children who participate in sport club activities declines with age, being 58\%, 44\%, and $35 \%$ at grades 5,7 , and 9, respectively. ${ }^{19}$ Boys participate more often than girls, but this gender difference seems to disappear with age. While children aged 7 to 14 years participate in sport club activities at least once per week (49\% of girls and $61 \%$ of boys), this percentage drops to $32 \%$ for ages 15 to 19 for both genders. ${ }^{18}$

Participation in sport club activities is popular in Finland; still, almost one-half of Finnish children and youth do not participate, although many express a willingness to do so. Clubs should consider ways to widen their membership. Participation in sport club activities enhances PA, both with regard to meeting the PA recommendations in adolescence and in later life. Although participation in sports contributes to higher levels of MVPA, for the majority of children who participate in sports, additional activities are needed to meet the current recommendations of 60 minutes of MVPA per day. ${ }^{20}$ Indeed, one-third of youth who participate in sport clubs do not meet the national PA recommendations. Furthermore, specializing in only 1 sport may hinder sampling various sports, reducing diverse experiences in sport and physical activities. More research is needed to clarify these phenomena that dilute efforts to understand and develop a complete system of organized sport.

\section{Active Play: C}

Active Play is graded $C(41 \%$ to $60 \%)$ based on results related to PA play outdoors in younger children and participation in unorganized PA alone or with friends. The improvement of this grade, which was a $D$ in 2014 , is based on a wider set of available data. Parents of Finnish children aged 3 to 6 years report that $63 \%$ of children play outdoors for at least 30 minutes per day on weekdays after day-care; further, $30 \%$ play outdoors for more than 2 hours per day on weekend days. ${ }^{10}$ Based on a recent survey, $52 \%$ of children aged 9 to 15 years participate in unorganized PA at least 4 times per week. ${ }^{17}$ In a 2013 study, the proportions of children aged 7 to 9,10 to 14 , and 15 to 19 who reported participation in unorganized PA almost daily by themselves were $36 \%, 49 \%$, and $33 \%$, respectively (with friends, these same groups reported $40 \%, 36 \%$, and $16 \%$, respectively). ${ }^{18}$ After comprehensive school, unorganized PA is relatively common: $41 \%$ of students in upper secondary school and $35 \%$ of students in vocational school participated in unstructured PA almost daily. ${ }^{21}$ Participation in active play and unorganized sport contributes substantially to overall PA levels in children and youth. More research is needed on active play and unorganized sport in Finland and its contribution to overall PA levels.

\section{Active Transportation: $B$}

Active Transportation is graded $B(61 \%$ to $80 \%)$ based on 5 different school-based surveys of 127,881 students aged 7 to $18 .{ }^{14,21-24}$ When all of the school commuting distances were included, $70 \%$ of primary and lower secondary school students and $75 \%$ of upper secondary school students commuted actively to school. However, it is also essential to consider the effect of commuting distance in the research on active commuting. For the $70 \%$ of the primary and lower secondary school students whose commuting distance to school was 3 kilometers or less, the prevalence of active school commute was approximately $85 \% \cdot{ }^{14,24}$ Although Finnish students are on average active commuters, there is large variation between schools. The cold and snowy Finnish winters also pose a challenge for active transportation, and more students are driven to school in that season. ${ }^{24}$ Therefore, there is more potential to increase PA through school commute in winter compared with spring and autumn. In addition to the school commute, more information about children's leisure time commuting is needed.

\section{Sedentary Behaviors: $D$}

The Sedentary Behaviors indicator is graded $D(21 \%$ to $40 \%)$ based on the low proportion of children and youth meeting the recommendations related to screen time on most days. Based on self-reports from a 2011 survey, about $25 \%$ of children spent less than 2 hours per day in front of television and computer screens as recommended. ${ }^{5,25}$ Sedentary behaviors have been measured by accelerometers (sedentary time) and by surveys focusing on screenbased sedentary behaviors.

In the last decade, the concept of 'screen time' has become problematic because different kinds of screens, including smartphones, are now an integral part of everyday life among teens. In addition, schoolwork often requires the use of screens and on the other hand, screen-based sedentary time comprises only a fraction of total sedentary time in children and youth. Therefore, data on total sedentary time has been included in this section, although there is no consensus on the recommended levels and criteria for children and youth. 
Based on parents' reports in 2016, the use of entertainment media is in general reasonable among children aged 3 to 6 years: the proportion of children using entertainment media for 2 hours or less per day is $97 \%$ during weekdays and $83 \%$ during weekends. ${ }^{10}$ However, in a 2016 survey of school-aged children, only $4 \%$ meet the screen time recommendation every day, and $25 \%$ meet the recommendation on at least 5 days per week from ages 9 to $15 .{ }^{17}$ The amount of screen time is higher on weekend days compared with weekdays, ${ }^{3}$ and on average, boys spend more time in front of screens compared with girls both during weekdays (2.4 versus 1.9 hours per day) and weekend days (4.0 versus 3.0 hours per day). ${ }^{14}$ Concerning different screen-based behaviors, gender difference is most obvious in digital playing: $50 \%$ of boys but only $11 \%$ of girls report playing computer or console games for 2 or more hours per day during weekdays in children aged 11 to $15 .{ }^{16}$

Accelerometers are valuable tools for measuring sedentary time. Based on accelerometer measurements, total sedentary time increased from 5.5 hours per day in children aged 3 to $6^{12}$ to 6.4 to 7.2 hours per day in primary school children ${ }^{11,14}$ and 8.2 hours per day in adolescents in lower secondary school. ${ }^{11}$ Daily sedentary time was higher for girls than boys, with the gender difference greater in primary school and lower in secondary school. ${ }^{3}$

More information is needed on the effects of sedentary behavior on children's health and well-being. Different types of screens are now part of daily life for children and youth; however, due to PA levels and high sedentary time, there is a need for novel tools to decrease excessive sitting and screen time among children and youth.

\section{Family and Peers: C}

The Family and Peers indicator is graded $C$ (41\% to 60\%) based on results related to children's reports on their parental and peer support for PA and participation in PA with them. ${ }^{17,18,26}$ Children aged 9 to 15 were asked to estimate parental support for their PA. Results showed that $79 \%$ of parents encouraged their children to be physically active, $62 \%$ parents transported/took them to physical activities, $37 \%$ were physically active with their children, and $77 \%$ contributed financially to their children's physical activities. ${ }^{17}$ Parental support for PA was more commonly reported by younger children aged 11 years compared with teens aged 15 years. ${ }^{26}$ More than half of young people consider that spending time with friends is an important motive for their participation in physical activities. ${ }^{18,26}$ In a 2016 survey, 44\% of children reported that their friends participated in sport with them-33\% reported that friends encouraged them to be physically active. ${ }^{17}$ However, when children were asked about the barriers to their own participation in PA, 26\% reported that their friends were not participating in sports, whereas $30 \%$ reported that sport and PA had a low level of appreciation among their friends. ${ }^{26}$ More information is needed on how to use peer support to promote PA among children and youth both at school (eg, during recess) and during leisure time.

\section{School: B}

School is graded $B(61 \%$ to $80 \%)$ based on the fact that $62 \%$ of all Finnish comprehensive schools (1564 out of 2523) are committed to enhancing PA during the school day and registered themselves for the FSM program (as of May 2016). These schools represent $73 \%$ of all students in basic education. ${ }^{9}$ The FSM program aims to establish a physically active culture in all comprehensive schools by 2018. Schools and municipalities participating in the program implement their own individual plans to increase PA during the school day. Schools have not increased obligatory PE in their curriculum; instead, they have chosen to increase it during recess, lessons, and before and after school. ${ }^{9}$

Typically, Finnish schools in basic education have 45 minutes of lessons and 15 minutes of recess. Almost all students in primary school (96\% in grade 5), but only 43\% (grade 9) in lower secondary school, usually spend recess outdoors. ${ }^{23}$ Similarly, participation in light PA during recess is common in primary school (58\% in grade 5), but this percentage drops drastically in lower secondary school (15\% in grade 1). ${ }^{23}$ Based on a 2015 survey $^{27}$ of school principals, $55 \%$ of schools had organized a longer recess period (eg, 20 to 35 minutes) for PA in the middle of the school day, and $76 \%$ reported that their schoolyard was suitable for neighborhood PA. In addition, $50 \%$ of schools reported that students acted as peer activators during recess $^{28} 24 \%$ of students took part in planning recess activities. ${ }^{17}$ Outside of school hours, $47 \%$ of the schools provided PA clubs ${ }^{28}$ and $23 \%$ of students aged 9 to 15 reported participating in school PA clubs at least once per week. ${ }^{17}$

On average, students have 100 minutes of compulsory PE per week in basic education in Finland, meaning 2 to 3 45-minute PE lessons per week. In addition, it is possible for students in lower and upper secondary school to take 2 to 6 elective PE lessons per week. PE is a popular school subject: $78 \%$ of boys and $65 \%$ of girls in grade 9 stated that they liked PE, and $60 \%$ of students wished their school offered more PE lessons. ${ }^{29}$ In Finland, the proportion of qualified teachers is high. Over $80 \%$ of PE teachers in lower secondary school, in upper secondary school and in vocational education are qualified to perform their task. In primary school, however, class educators teach PE as well as all other subjects, and only some of them are qualified PE taeachers. ${ }^{30}$ Opportunities and facilities that support PE and PA in school vary, but $75 \%$ of principals in upper secondary schools stated that they have adequate gymnasiums, sporting fields and equipment. ${ }^{29}$

Children and youth accumulate $34 \%$ of all daily MVPA and as much as $47 \%$ of all daily sedentary time during the school day. ${ }^{11}$ School provides an important arena to promote a physically active lifestyle because in this setting, all age groups can be reached regardless of their earlier experience, motivation, and attitude towards PA. High-quality PE and other school-day PA at recess and in the classroom contribute to Finland's goal of 60 minutes of PA per day for all children and youth.

\section{Community and the Built Environment: $B$}

The Community and the Built Environment indicator is graded $B$ (61\% to $80 \%$ ) because in $2014,63 \%$ of municipalities reported that they had covered PA promotion in their strategy document; further, $62 \%$ of municipalities had a plan for developing neighborhood PA facilities. ${ }^{31}$ Most municipalities support children's sport. In 65\% of municipalities, the use of the school gym is free for local sport clubs that organize PA for children and adolescents, and the use of sport and playing fields is free for children's sports in $78 \%$ of municipalities. ${ }^{31}$ In general, the average number of sport facilities in Finnish municipalities is relatively high, at 9.3 per 1000 residents in 2014. ${ }^{31}$ In addition, pedestrian and bike lanes are maintained by municipalities and offer an important channel for physically active commuting. Municipalities play an important role in several sectors in making decisions that affect the 60 minutes per day PA goal. 


\section{Government: $B$}

The indicator for Government Strategies, Policies, and Investments is graded $B(61 \%$ to $80 \%)$ because clear and effective national policy documents and strategies as well as investments to enhance PA among children and youth are in place. The New Sport Act was enacted in 2015 to regulate PA aims at the governmental level. One of the aims is to support children's growth and development, coordinated by the Ministry of Education and Culture. The state budget for enhancing PA and sports, delivered mainly through the Ministry of Education and Culture, was $148 \mathrm{M} €$ in 2015 ( $28 €$ per inhabitant). Targeted subsidies for children's and youth's PA varied from 5.4 to 9 M€ during 2012 to $2014 .{ }^{32}$ In the strategic program, the current government has stated that "The 'Schools on the Move' project will be expanded across the country to ensure 60 minutes of physical activity each day,' 6 and 21 $\mathrm{M} €$ has been allocated to the municipalities via FSM program for 2016 to 2018. Other ministries have the potential to influence PA promotion in many ways. For instance, in 2013, the Ministry of Social Affairs and Health and the Ministry of Education and Culture adopted a national strategy entitled 'On the Move' to promote PA for health and well-being up to the year 2020. ${ }^{33}$ The Ministry of Transport and Communications has created the National Strategy for Walking and Cycling 2020, including a goal to grow the number of trips made by cycling and walking by $20 \% .{ }^{34}$

\section{Strengths and Limitations}

The strengths of Finland's 2016 Report Card include the opportunity to use several datasets and get the latest unpublished information directly from researchers. Several datasets are based on nationwide study samples, and both objective and self-reported measurements are available. Compared with the 2014 Report Card, more data based on objective PA were available, especially for young children. However, more information on active transport other than school commute, PA play and participation in unorganized PA at different ages is needed.

\section{Conclusion}

Despite good policies and programs to promote PA in Finland, children and youth overall levels of PA are low, whereas their time spent sedentary is high. More effective interventions, operation models, means, concrete tools as well as environmental solutions are needed to support changes toward more physically active childhood and youth.

\section{Acknowledgments}

The authors thank Jari Villberg from the University of Jyväskylä for help with the data request. This work was supported by a grant from the Ministry of Education and Culture of Finland.

\section{References}

1. Suomi.fi webpages, a one-stop portal for Finnish public sector online services for citizens. www.suomi.fi. Accessed May 25, 2016.

2. The Finnish Meteorological Institute. http://en.ilmatieteenlaitos.fi/. Accessed May 25, 2016.

3. Tammelin T, Laine K, Turpeinen S. Physical Activity of School-aged Children. LIKES Research Reports on Sport and Health 272. Finnish report, abstract in English. Jyväskylä, Finland: LIKES - Foundation for Sport and Health Sciences; 2013.

4. Finnish National Board of Education. 2016 http://www.oph.fi/english/ education_system. Accessed May 25, 2016.

5. Ministry of Education and Young Finland Association. Recommendations for the Physical Activity of School-aged Children. Finnish report, abstract in English. Helsinki: Reprotalo Lauttasaari; 2008.

6. Finland, a land of solutions. Strategic Programme of Prime Minister Juha Sipilä's Government 29 May 2015. Government Publications $12 / 2015$.

7. Colley RC, Brownrigg M, Tremblay MS. A model of knowledge translation in health: the Active Healthy Kids Canada Report Card on physical activity for children and youth. Health Promot Pract. 2012;13(3):320-330. PubMed doi:10.1177/1524839911432929

8. Kokko S, Hämylä R. The Physical Activity Behaviours of Children and Adolescents in Finland. Results of the LIITU study. Finnish report, abstract in English. Publications of the National Sports Council; 2015:2.

9. Finnish Schools on the Move programme. http://www.liikkuvakoulu. fi/. Accessed May 25, 2016.

10. Sääkslahti A. Taitavat tenavat results. Unpublished information; 2016.

11. Tammelin T, Kulmala J, Hakonen H, Kallio J. School Makes You Move and Sit Still. Finnish Schools on the Move research results from 2010 to 2015. LIKES - Research Center for Sport and Health Sciences / Finnish Schools on the Move programme; 2015.

12. Soini A. Always on the Move? Measured Physical Activity of 3-yearold Preschool Children. University of Jyväskylä, Studies in Sport, Physical Education and Health; 2015.

13. Husu P, Vähä-Ypyä H, Vasankari T. Objectively measured sedentary behavior and physical activity of Finnish 7- to 14-year-old childrenassociations with perceived health status: a cross-sectional study. BMC Public Health. 2016;16(1):338 doi:10.1186/s12889-016-3006-0. PubMed

14. Husu P. Results of the Naantali Schools on the Move study 2013. Unpublished information; 2016.

15. Inchley J, Currie D, Young T, et al, eds. Growing up Unequal: Gender and Socioeconomic Differences in Young People's Health and Wellbeing. Health Behaviour in School-aged Children (HBSC) Study: International Report From the 2013/2014 Survey. Copenhagen: WHO Regional Office for Europe (Health Policy for Children and Adolescents no. 7); 2016.

16. Tynjälä J. HBSC results in Finland, year 2014. Unpublished information; 2016.

17. Kokko S. Results of the LIITU study 2016. Unpublished information; 2016.

18. Myllyniemi S, Berg P. Young People on the Go! Study of Young People's Leisure Activities. Finnish report, abstract in English. Verkkojulkaisuja, Nuorisotutkimusseura, nro 64; 2013.

19. Blomqvist M, Mononen K, Konttinen K, Koski P, Kokko S. Urheilu ja seuraharrastaminen. In: Kokko S, Hämylä R eds. The Physical Activity Behaviours of Children and Adolescents in Finland. Results of the LIITU study. Finnish report, abstract in English. Publications of the National Sports Council; 2015:2, 74-82.

20. Ekelund U, Tomkinson G, Armstrong N. What proportion of youth are physically active? Measurement issues, levels and recent time trends. Review Br J Sports Med. 2011;45(11):859-865 doi:10.1136/ bjsports-2011-090190. PubMed

21. THL (National Institute for Health and Welfare). Results of School Health Promotion Study. https://www.thl.fi/fi/tutkimus-ja-asiantuntijatyo/vaestotutkimukset/kouluterveyskysely/tulokset; 2015. 
22. Paronen O, Aittasalo M, Jussila A-M. Kasit liikkeelle! Koulumatka- ja liikuntakysely Tampereella syksyllä 2011. Finnish report. Tampere: UKK-instituutti, Tampereen kaupunki; 2012.

23. Turpeinen S, Kallio J, Haapala H, Rajala K, Lehtomäki M, Tammelin T. Välitunti- ja koulumatkaliikunta. In: Kokko S, Hämylä R eds. The Physical Activity Behaviours of Children and Adolescents in Finland. Results of the LIITU study. Finnish report, abstract in English. Publications of the National Sports Council; 2015:2, 57-64.

24. Tammelin T. Finnish Schools on the Move study. Unpublished information; 2016.

25. Tremblay MS, Leblanc AG, Janssen I, et al. Canadian sedentary behaviour guidelines for children and youth. Appl Physiol Nutr Metab. 2011;36(1):59-64. PubMed doi:10.1139/H11-012

26. Palomäki S, Huotari P, Kokko S. Vanhemmat ja kaverit liikuntaharrastuksen tukena. In: Kokko S, Hämylä R eds. The Physical Activity Behaviours of Children and Adolescents in Finland. Results of the LIITU study. Finnish report, abstract in English. Publications of the National Sports Council; 2015:2, 66-71

27. Ståhl T. TEAviisari 2015. Promotion of Health and Welfare in Comprehensive Schools. Unpublished information; 2016.
28. Kämppi K, Aira A, Inkinen V, Laine K. Self-evaluation Tool for PA Promotion in Schools 2015-2016. Unpublished information; 2016.

29. Palomäki S, Heikinaro-Johansson P. Liikunnan oppimistulosten seuranta-arviointi perusopetuksessa 2010. Koulutuksen seurantaraportit 2011:4. Opetushallitus.

30. Kumpulainen T (ed). Opettajat Suomessa 2013. Koulutuksen seurantaraportit 2014:8. Opetushallitus; 2014.

31. Hakamäki P, Aalto-Nevalainen P, Saaristo V, Ståhl T. Liikunnan edistäminen kunnissa 2010-2014. Seurantaraportti. Opetus- ja kulttuuriministeriön julkaisuja 2015:18.

32. Valtion liikuntaneuvosto. Valtionhallinto liikunnan edistäjänä 20112015. Finnish report. Valtion liikuntaneuvoston julkaisuja 2015:4.

33. On the Move-National Strategy for Physical Activity Promoting Health and Wellbeing 2020. Publications of the Ministry of Social Affairs and Health; 2013:14.

34. National Strategy for Walking and Cycling 2020. Ministry of Transport and Communications, Programmes and strategies 4/2011. Helsinki; 2011. 